Article No 228

DOI: https://doi.org/10.26881/srg.2020.7.03

Citation:

Фролова, О. (2020). Референция официального текста.

Studia Rossica Gedanensia, 7: 38-48. DOI:

https://doi.org/10.26881/srg.2020.7.03

Frolova, O. (2020). Referenciâ oficial'nogo teksta. Studia Rossica Gedanensia, 7: 38-48.

DOI: https://doi.org/10.26881/srg.2020.7.03

\title{
РЕФЕРЕНЦИЯ ОФИЦИАЛЬНОГО ТЕКСТА ${ }^{1}$
}

\author{
ОЛЬГА Е. ФРОЛОВА / OLGA Е. FROLOVA
}

Московский государственный университет имени М. В. Ломоносова /

Lomonosov Moscow State University

Филологический факультет / Faculty of Philology

Межкафедральная лаборатория фонетики и речевой коммуникации /

Laboratory of Phonetics and Speech Communication

Ленинские горы, д. 1, 1 гуманит. корпус, к. 948, 119991, Москва, Россия /

Leninskiye Gory 1, apt. 948, 119991, Moscow, Russia

ORCID: http://orcid.org/0000-0002-7667-236X

E-mail: olga_frolova@list.ru

(Получено / Received 30.10.2020. Принято / Accepted 8.11.2020)

\section{Abstract \\ Official text reference}

The article examines the reference of the official text on the example of the decrees of the mayor of Moscow for the period March-June 2020. The logical-semantic and pragmatic aspects of reference are considered. Specific reference noun phrases in the texts name the participants who organize and carry responsibility for the assistance to the population. Noun phrases used to name the loci of infection are also referencespecific. Nominal groups that name the addressee of help do not refer to any specific objects of extra-linguistic reality. The text analysis carried out with the Istio.com pro-

1 Статья в рамках проекта РФФИ 17-29-09158 «Создание корпуса официально-деловых текстов русского языка (ОДКРЯ)» 
gram allows one to determine the frequency of vocabulary, which shows the degree of importance of the participant of the situation for the speaker.

Thus, in the text compiled from the decrees of the mayor of Moscow for the period from March to June 2020, the focus of the addressee's attention is the noun citizen, which indicates the aim of the text and the importance of the participants of the situation for the sender.

Key words: reference, noun phrase, official text, participant in a situation, frequency, focus

\section{Резюме}

В статье рассматривается референция официального текста на примере указов мэра Москвы за период март-июнь 2020 г. Были рассмотрены логико-семантический и прагматический аспекты референции. Конкретно-референтные именные группы в текстах называют участников ситуации, организующих помощь населению и отвечающих за это. Конкретно-референтны также именные группы, называющие локусы заражения. Именные группы, называющие адресата помощи, не относятся к конкретным объектам внеязыковой действительности. Анализ текста с помощью программы Istio.com позволяет определить частотность лексики, а это показывает степень значимости участника ситуации для говорящего.

Так в тексте, составленном из указов мэра Москвы за период с марта по июнь 2020 г., в фокусе внимания адресанта оказывается имя существительное гражданин, что свидетельствует о направленности текста и важности для говорящего данного участника ситуации.

Ключевые слова: референция, именная группа, официальный текст, участник ситуации, частотность, фокус

Традиционно под референцией понимают «отнесённость актуализованных (включённых в речь) имён, именных выражений (именных групп) или их эквивалентов к объектам действительности (референтам, денотатам). Референция определяется тремя основными факторами: синтаксическим, логико-семантическим и прагматическим» (Арутюнова 1990: 411). В рамках синтаксического аспекта выделяются именные группы (далее - ИГ) в позициях актантов, логико-семантический аспект «отвечает» за типы отнесенности к объектам внеязыковой действительности, а прагматический отражает влияние на референцию того, как адресант учитывает знания адресата о предмете речи (см. Арутюнова 1990). Денотативные статусы ИГ проанализированы в монографии Е.В. Падучевой (Падучева 1985). 
Референтность и нереферентность употребления ИГ в высказываниях, принадлежащих разным жанрам и созданных в рамках разных функциональных стилей, - общая закономерность лингвистики речи.

Однако жанровые и функционально-стилистические характеристики текста все же влияют на особенности его референции. Так, официально-деловым, и в частности, законодательным текстам присущи безличность изложения, что выражается в пассивных конструкциях, а это, в свою очередь позволяет опустить актанты в позиции субъекта (Крысин 2020: 451; Крылова 2006: 156).

Мы намереваемся рассмотреть референцию законодательных текстов одного жанра, принадлежащих одному автору, созданных в период с марта по июнь 2020 г. - указов мэра Москвы (далее - УММ), посвященных мерам противодействия коронавирусу в российской столице.

Цель - определить приоритеты адресанта в отражении структуры экстралингвистической ситуации, а также выявить более и менее важных участников ситуации, с точки зрения говорящего.

Материал - тексты 19 указов мэра Москвы, опубликованных на страницах «Российской газеты» и выложенных на ее официальном сайте.

Экстралингвистическая ситуация может быть смоделирована следующим образом: население города (A) подверглось распространяющемуся тяжелому заболеванию (B), и руководитель местной власти (C) организует ряд мер (D), имеющих целью предотвратить распространение эпидемии (E) и вылечить заболевших (F).

Первым документом, в котором были объявлены меры по борьбе с коронавирусом, стал УММ от 05.02.2020.

Анализ текста позволяет выделить классы ИГ, относящихся к описанной нами структуре экстралингвистической ситуации.

(А) гражданин, посещавший территории, где зарегистрированы случаи новой коронавирусной инфекции;

гражданин, прибывщий из Китайской Народной Республики ..., а также других государств;

больной с респираторными симптомами;

работник,

заболевший

(В) случай новой коронавирусной инфекиии; распространение новой коронавирусной инфекции;

неблагополучная ситуация с распространением новой коронавирусной инфекции;

(B1) симптомы:

респираторные симптомы;

(C) $м э р$;

заместитель мэра Москвы в Правительстве Москвы;

заместитель Мэра Москвы в Правительстве Москвы по вопросам градостроительной

политики и строительства; 
(D) проработка вопроса создания инфекционного корпуса с использованием быстровозводимых конструкиий; усиление выездной амбулаторной службы;

(Е) информация о всех контактах заболевмего новой коронавирусной инфекцией; самоизоляция;

(F) помощьь больным;

оформление листков нетрудоспособности.

Конкретно-референтны ИГ в классе (C), называющие учреждения и лиц, ответственных за проведение антиэпидемиологических мер.

Что касается класса (А), именные группы имеют неопределенный денотативный статус.

(1) При поступлении запроса Управления Федеральной службы по надзору в сфере защиты прав потребителей и благополучия иеловека по городу Москве незамедлительно представлять инбормацию о всех контактах заболевщего новой коронавирусной инфекиией (2019-nCoV) в связи с исполнением им трудовых функиий, обеспечить проведение дезинфекиии помещений, где находился заболевший (УММ 05.03.2020).

За ИГ человек и заболевший не стоят никакие конкретные объекты внеязыковой действительности.

(2) Обязать всех работодателей, осуществляющци деятельность на территории города Москвы:

Обеспечить измерение температуры тела работникам на рабочих местах

с обязательным отстранением от нахождения на рабочем месте лии с повыменной температурой.

Оказывать работникам содействие в обеспечении соблюдения режима самоизоляции на дому (УММ 05.03.2020).

ИГ все работодатели относится к конкретному исчерпывающему множеству, а что касается ИГ работники, ее денотативный статус не конкретен.

(3) Организовать работу медицинских организаций с приоритетом оказания медицинской помощи на дому лихорадящим больным с респираторными симптомами, посещавшим территории, где зарегистрированы случаи новой коронавирусной инфекции (УММ 05.03.2020).

В примере (3) ИГ медицинские организации конкретно-референтна, на данные учреждения возлагаются определенные обязанности по оказания помощи заболевшим.

Обращение к тексту позволило выделить и еще один класс участников экстралингвистической ситуации, не учтенных нами при предварительном моделировании, - названия стран и территорий, откуда приезжали граждане, ставшие источником заражения.

(A1) Китайская Народная Республика, Республика Корея, Итальянская Республика, Исламская Республика Иран, Франиузская Республика, Федеративная Республика Германии, Королевство Испании, а также другие государства с неблагополучной ситуацией. 
В УММ от 05.03.2020 можно говорить о трех типах употребления ИГ с разными денотативными статусами: конкретно-референтное употребление ИГ наблюдаем в номинациях а) лиц и учреждений, отвечающих за организацию помощи населению, б) стран, откуда могли приехать лица, ставшие источником заражения; неопределенный денотативный статус ИГ встречается у номинаций а) заболевших и б) работников различных учреждений Москвы.

С нашей точки зрения, в рамках прагматического аспекта референции текста, целесообразно также учитывать коммуникативное намерение адресанта. Мы исходим из того, что номинации наиболее важных актантов для адресанта будут иметь и большую частотность по сравнению с менее важными, т.е. мы хотим описать набор участников ситуации, отраженной в тексте, и их статусы в том виде, как моделирует ее адресант.

Инструментом выступит программа Istio.com, предназначенная для спичрайтеров, позволяющая оценить стилистическую сбалансированность и легкость восприятия текста. Программа определяет также объем текста в знаках с пробелами и без, в словах, а также выделяет ядро текста, отсекая служебные слова - предлоги и союзы, которые получили название cmon-слова, далее программа определяет словарь ядра текста и частотность лексических единиц всего текста и его ядра.

Вначале покажем состав наиболее частотных единиц первого УММ от 5 марта 2020 г.

Таблица 1. Квантитивные характеристики УММ от 05.03.2020

\begin{tabular}{|l|l|l|}
\hline $\begin{array}{l}\text { Текст } \\
\text { УММ от 05.03.2020 }\end{array}$ & Параметр & Значение \\
\hline & Длина с пробелами ? & 4728 символов \\
\hline & Длина без пробелов ? & $\mathbf{4 1 5 7}$ символов \\
\hline & Всего слов ? & 546 \\
\hline & Словарь ? & 266 слов \\
\hline & Словарь ядра ? & 218 слов \\
\hline
\end{tabular}

В верхней части таблицы 2 отображается количество и процентное соотношение ключевых фраз в ядре и тексте.

Программа Istio.com определяет количество употреблений слова в тексте третий, релевантность - четвертый, процентное значение употреблений в ядре - пятый и в тексте с учетом служебных слов - шестой столбец слева.

В Таблице 2 мы видим 20 наиболее частотных единиц текста УММ от 05.03.2020. В список наиболее частотных вошли единицы, называющие лиц и учреждения, ответственные за эпидемиологическую обстановку в столице (мэр, служба), названия юридических законодательных документов (указ), источник опасности (инфекция, $-n c o v)$, названия локусов, обозначающих территорию ответственности (город, Москва) и источник потенциальной эпидемиоло- 
Таблица 2. Анализ частотности УММ 05.03.2020

\begin{tabular}{|c|c|c|c|c|c|}
\hline$\#$ & Слово & Кол-во? & Рел. ? & \% в ядре ? & \% в тексте? \\
\hline 1 & Москва & 19 & 4.24 & $4.8 \%$ & $3.4 \%$ \\
\hline 2 & город & 11 & 2.45 & $2.8 \%$ & $2 \%$ \\
\hline 3 & медицинский & 9 & 2.01 & $2.2 \%$ & $1.6 \%$ \\
\hline 4 & инфекция & 9 & 2.01 & $2.2 \%$ & $1.6 \%$ \\
\hline 5 & - ncov & 8 & 1.78 & $2 \%$ & $1.4 \%$ \\
\hline 6 & обеспечить & 8 & 1.78 & $2 \%$ & $1.4 \%$ \\
\hline 7 & организация & 6 & 1.34 & $1.5 \%$ & $1 \%$ \\
\hline 8 & территория & 6 & 1.34 & $1.5 \%$ & $1 \%$ \\
\hline 9 & республика & 6 & 1.34 & $1.5 \%$ & $1 \%$ \\
\hline 10 & коронавирусной & 6 & 1.34 & $1.5 \%$ & $1 \%$ \\
\hline 11 & помощь & 5 & 1.11 & $1.2 \%$ & $0.9 \%$ \\
\hline 12 & мэр & 5 & 1.11 & $1.2 \%$ & $0.9 \%$ \\
\hline 13 & дом & 5 & 1.11 & $1.2 \%$ & $0.9 \%$ \\
\hline 14 & режим & 5 & 1.11 & $1.2 \%$ & $0.9 \%$ \\
\hline 15 & ситуация & 4 & 0.89 & $1 \%$ & $0.7 \%$ \\
\hline 16 & работа & 4 & 0.89 & $1 \%$ & $0.7 \%$ \\
\hline 17 & служба & 4 & 0.89 & $1 \%$ & $0.7 \%$ \\
\hline 18 & указ & 4 & 0.89 & $1 \%$ & $0.7 \%$ \\
\hline 19 & распространение & 4 & 0.89 & $1 \%$ & $0.7 \%$ \\
\hline 20 & место & 4 & 0.89 & $1 \%$ & $0.7 \%$ \\
\hline
\end{tabular}

гической опасности (республика, территория), меры воздействия на ситуацию (медицинская помощь, режим). Показательно, что прилагательное медицинский, входящее в состав ИГ медицинская организация и медииинская помощь, занимает третье место среди самых частотных единиц ядра текста. Следует отметить факт отсутствия среди наиболее частотных единиц слов, называющих адресат помощи: гражданин (2 употребления - 0,5\%), население (1 употребление - 0,2\%), житель (не встречается в тексте), больной (не встречается в тексте), заболевший (1 употребление - 0,2\%).

Далее мы предприняли следующий шаг, имеющий целью выяснение состава ИГ и частотности лексики корпуса 19 указов мэра за период с марта по июнь 2020 г. Тексты принадлежат одном адресанту и жанру и сохраняют свою композицию. Тексты, включая УММ от 05.03.2020 г., были скопированы и объединены в один. Далее этот текст был обработан с помощью программы Istio.com. 
Таблица 3. Квантитивные характеристики текстов УММ

\begin{tabular}{|l|l|l|}
\hline $\begin{array}{l}\text { Текст } \\
\text { УММ март-июнь 2020 }\end{array}$ & Параметр & Значение \\
\hline & Длина с пробелами ? & 582930 символов \\
\hline & Длина без пробелов ? & $\mathbf{5 0 9 2 7 7 с и м в о л о в ~}$ \\
\hline & Всего слов ? & $\mathbf{6 7 6 7 5}$ \\
\hline & Водность $?$ & $33 \%$ \\
\hline & Тошнота ? & 55.01 \\
\hline & Словарь ? & 1599 слов \\
\hline & Словарь ядра ? & 1433 слов \\
\hline
\end{tabular}

Таблица 4. Анализ УММ за период первой волны пандемии

\begin{tabular}{|l|l|c|c|c|c|}
\hline & Слово & Кол-во & Рел.? & $\begin{array}{l}\text { \% в } \\
\text { ядре? }\end{array}$ & \% в тексте? \\
\hline 1 & Москва & 1216 & 22.1 & $2.7 \%$ & $1.7 \%$ \\
\hline 2 & город & 853 & 15.5 & $1.8 \%$ & $1.2 \%$ \\
\hline 3 & указ & 797 & 14.48 & $1.7 \%$ & $1.1 \%$ \\
\hline 4 & гражданин & 791 & 14.37 & $1.7 \%$ & $1.1 \%$ \\
\hline 5 & организация & 612 & 11.12 & $1.3 \%$ & $0.9 \%$ \\
\hline 6 & режим & 533 & 9.68 & $1.1 \%$ & $0.7 \%$ \\
\hline 7 & -ум & 444 & 8.07 & $0.9 \%$ & $0.6 \%$ \\
\hline 8 & услуга & 435 & 7.9 & $0.9 \%$ & $0.6 \%$ \\
\hline 9 & территория & 430 & 7.81 & $0.9 \%$ & $0.6 \%$ \\
\hline 10 & пункт & 414 & 7.52 & $0.9 \%$ & $0.6 \%$ \\
\hline 11 & деятельность & 399 & 7.25 & $0.8 \%$ & $0.5 \%$ \\
\hline 12 & порядок & 357 & 6.48 & $0.7 \%$ & $0.5 \%$ \\
\hline 13 & март & 345 & 6.27 & $0.7 \%$ & $0.5 \%$ \\
\hline 14 & обеспечить & 338 & 6.14 & $0.7 \%$ & $0.4 \%$ \\
\hline 15 & число & 333 & 6.05 & $0.7 \%$ & $0.4 \%$ \\
\hline 16 & приложение & 319 & 5.79 & $0.7 \%$ & $0.4 \%$ \\
\hline 17 & мэр & 318 & 5.77 & $0.7 \%$ & $0.4 \%$ \\
\hline 18 & место & 312 & 5.67 & $0.6 \%$ & $0.4 \%$ \\
\hline 19 & апрель & 306 & 5.56 & $0.6 \%$ & $0.4 \%$ \\
\hline 20 & медицинский & 292 & 5.3 & $0.6 \%$ & $0.4 \%$ \\
\hline
\end{tabular}


Текст УММ за март-июнь показывает как зоны стабильности, так изменения в картине частотности. Среди конкретно-реферетных ИГ, называющие локусы, Москва и город, возглавляют Таблицу 2 и Таблицу 4. Различия заключаются в следующем: из 20 наиболее частотных единиц «уходит» ИГ, называющая угрозу - инфекция (223 употребления - 0,4\%). Понижается частотность прилагательного медицинский, которое входит в ИГ медицинская организация и медицинское изделие. В сравнении с таблицей, посвященной УММ от 05.03.2020, интересную "рокировку» наблюдаем в повышении частотного статуса ИГ гражданин, денотативный статус которой варьируется, и конкретно-референтной ИГ мэр, которая опускается по частотности на более низкую позицию, ИГ гражданин называет адресата, а мэр - адресанта помощи.

Подведем итоги. Мы рассматривали референцию официального текста на материале одного текста и корпуса текстов одного жанра и одного автора. Среди ИГ с конкретной референцией были номинации лиц и учреждений, отвечающих за организацию специального режима в Москве во время пандемии. ИГ с неопределенной референцией называли адресата медицинской помощи. Была предпринята попытка проанализировать референцию текста с учетом коммуникативного намерения адресанта, который может акцентировать свое внимание на некоторых актантах ситуации и уводить на периферию другие. Инструментом выявления фокуса внимания адресанта может быть анализ частотности лексики текста. Сравнение употребления ИГ гражданин и мэр в единичном тексте и корпусе текстов демонстрирует изменение частотности: в корпусе ИГ гражданин как адресат помощи показывает более высокую частотность, a ИГ мэр как актант, обеспечивающий оказание помощи, уходит на менее частотную позицию. Данное обстоятельство можно объяснить как фокусирование внимания на адресате помощи.

\section{Библиография / References}

Arutûnova,N.D. (1990). Referenciâ. B: Lingvističeskij ènciklopedičeskij slovar'. Gl. red. V.N. Ârceva. Moskva: Sovetskaâ ènciklopediâ: 411-412 [Арутюнова, Н.Д. (1990). Референция. В: Лингвистический энциклопедический словарь. Гл. ред. В.Н. Ярцева. Москва: Советская энциклопедия: 411-412].

Istio. (Online) https://istio.com/rus/text/analyz/ (доступ 10.10.2020).

Krylova, O.A. (2006). Lingvističeskâ̂ stilistika. Kn. 1: Teoriâ. Moskva: Vysšaâ škola [Крылова, O.A. (2006). Лингвистическая стилистика. Кн. 1: Теория. Москва: Высшая школа].

Krusin, L.L. (2020). Oficial'no-delovojstil'. B: Russkij âzyk: Ėnciklopediâ. Pod obŝ. red. A.M. Moldovana. 3-eizd. pereb. i dop. Moskva: AST-PRESS škola [Крысин, Л.Л. (2020). Официально-деловой стиль. В: Русский язык: Энииклопедия. Под общ. ред. А.М. Молдована. 3-е изд. переб. и доп. Москва: АСТ-ПРЕСС школа].

Padučeva, E.V. (1985). Vyskazyvanie i ego sootnesennost's dejstvitel'nost'û. Moskva: Nauka [Падучева, Е.В. (1985). Высказывание и его соотнесенность с действительностью. Москва: Наука].

Ukaz mèra Moskvy ot 5 marta 2020 goda № 12-UM «O vvedenii režima povyšennoj gotovnosti». Rossijskâ̂ gazeta, 5.03.2020. (Online) https://rg.ru/2020/03/05/moscow-ukaz12-reg-dok.html (dostup 10.10.2020) [Указ мэра Москвы от 5 марта 2020 года № 12-УМ «О введении режима 
повышенной готовности». Российская газета, 5.03.2020. (Online) https://rg.ru/2020/03/05/ moscow-ukaz12-reg-dok.html (доступ 10.10.2020)].

Ukaz mèra Moskvy ot 10 marta 2020 goda № $17-\mathrm{UM}$ «O vnesenii izmeneniâ v ukaz Mèra Moskvy ot 5 marta 2020 goda № 12-UM». Rossijskaâ gazeta, 10.03.2020. (Online) https:// rg.ru/2020/03/10/moscow-ukaz17-reg-dok.html (dostup 10.10.2020) [Указ мэра Москвы от 10 марта 2020 года № 17-УМ «О внесении изменения в указ Мэра Москвы от 5 марта 2020 г. № 12-УМ». Российская газета, 10.03.2020. (Online) https://rg.ru/2020/03/10/moscowukaz17-reg-dok.html (доступ 10.10.2020)].

Ukaz mèra Moskvy ot 16 marta 2020 goda № 21-UM «O vnesenii izmeneniâ v ukaz Mèra Moskvy ot 5 marta 2020 goda № 12-UM». Rossijskaâ gazeta, 6.03.2020. (Online) https:// rg.ru/2020/03/16/moscow-ukaz21-reg-dok.html (dostup 10.10.2020) [Указ мэра Москвы от 16 марта 2020 года № 21-УМ «О внесении изменения в указ Мэра Москвы от 5 марта 2020 г. № 12-УМ». Российская газета, 6.03.2020. (Online) https://rg.ru/2020/03/16/moscowukaz21-reg-dok.html (доступ 10.10.2020)].

Ukaz mèra Moskvy ot 19 marta 2020 goda № 25-UM «O vnesenii izmeneniâ v ukaz Mèra Moskvy ot 5 marta 2020 goda № 12-UM». Rossijskâ̂ gazeta, 6.03.2020. (Online) https:// rg.ru/2020/03/19/moscow-ukaz25-reg-dok.html (dostup 10.10.2020) [Указ мэра Москвы от 19 марта 2020 года № 25-УМ «О внесении изменений в указ Мэра Москвы от 5 марта 2020 г. № 12-УМ». Российская газета, 6.03.2020. (Online) https://rg.ru/2020/03/19/moscow-ukaz25reg-dok.html (доступ 10.10.2020)].

Ukaz mèra Moskvy ot 23 marta 2020 goda № 26-UM «O vnesenii izmeneniâ v ukaz Mèra Moskvy ot 5 marta 2020 goda № 12-UM». Rossijskaâ gazeta, 23.03.2020. (Online) https:// rg.ru/2020/03/23/moscow-ukaz26-reg-dok.html (dostup 10.10.2020) [Указ мэра Москвы от 23 марта 2020 года № 26-УМ «О внесении изменений в указ Мэра Москвы от 5 марта 2020 г. № 12-УМ». Российская газета, 23.03.2020. (Online) https://rg.ru/2020/03/23/moscowukaz26-reg-dok.html (доступ 10.10.2020)].

Ukaz mèra Moskvy ot 25 marta 2020 goda № 28-UM «O vnesenii izmeneniâ v ukaz Mèra Moskvy ot 5 marta 2020 goda № 12-UM». Rossijskaâ gazeta, 25.03.2020. (Online) https:// rg.ru/2020/03/25/moscow-ukaz28-reg-dok.html (dostup 10.10.2020) [Указ мэра Москвы от 25 марта 2020 года № 28-УМ «О внесении изменений в указ Мэра Москвы от 5 марта 2020 г. № 12-УМ». Российская газета, 25.03.2020. (Online) https://rg.ru/2020/03/25/moscow-ukaz28-reg-dok.html (доступ 10.10.2020)].

Ukaz mèra Moskvy ot 27 marta 2020 goda № 33-UM «O vnesenii izmeneniâ v ukaz Mèra Moskvy ot 5 marta 2020 goda № 12-UM». Rossijskaâ gazeta, 27.03.2020. (Online) https:// rg.ru/2020/03/27/moscow-ukaz33-reg-dok.html (dostup 10.10.2020) [Указ мэра Москвы от 27 марта 2020 года № 33-УМ «О внесении изменений в указ Мэра Москвы от 5 марта 2020 г. № 12-УМ». Российская газета, 27.03.2020. (Online) https://rg.ru/2020/03/27/moscowukaz33-reg-dok.html (доступ 10.10.2020)].

Ukaz mèra Moskvy ot 29 marta 2020 goda № 34-UM «O vnesenii izmeneniâ v ukaz Mèra Moskvy ot 5 marta 2020 goda № 12-UM». Rossijskaâ gazeta, 29.03.2020. (Online) https:// rg.ru/2020/03/29/moscow-ukaz34-reg-dok.html (dostup 10.10.2020) [Указ мэра Москвы от 29 марта 2020 года № 34-УМ «О внесении изменений в указ Мэра Москвы от 5 марта 2020 г. № 12-УМ». Российская газета, 29.03.2020. (Online) https://rg.ru/2020/03/29/moscowukaz34-reg-dok.html (доступ 10.10.2020)].

Ukaz mèra Moskvy ot 2 aprelâ 2020 goda № 36-UM «O vnesenii izmeneniâ v ukaz Mèra Moskvy ot 5 marta 2020 goda № 12-UM». Rossijskaâ gazeta, 2.04.2020. (Online) https://rg.ru/2020/04/02/ moscow-ukaz36-reg-dok.html (dostup 10.10.2020) [Указ мэра Москвы от 2 апреля 2020 года № 36-УМ «О внесении изменений в указ Мэра Москвы от 5 марта 2020 г. № 12-УМ». 
Российская газета, 2.04.2020. (Online) https://rg.ru/2020/04/02/moscow-ukaz36-reg-dok. html (доступ 10.10.2020)].

Ukaz mèra Moskvy ot 4 aprelâ 2020 goda № 39-UM «O vnesenii izmeneniâ v ukaz Mèra Moskvy ot 5 marta 2020 goda № 12-UM». Rossijskaâ gazeta, 4.04.2020. (Online) https://rg.ru/2020/04/04/ moscow-ukaz39-reg-dok.html (dostup 10.10.2020) [Указ мэра Москвы от 4 апреля 2020 года № 39-УМ «О внесении изменений в указ Мэра Москвы от 5 марта 2020 г. № 12-УМ». Российская газета, 4.04.2020. (Online) https://rg.ru/2020/04/04/moscow-ukaz39-reg-dok. html (доступ 10.10.2020)].

Ukaz mèra Moskvy ot 10 aprelâ 2020 goda № 42-UM «O vnesenii izmeneniâ v ukaz Mèra Moskvy ot 5 marta 2020 goda № 12-UM». Rossijskaâ gazeta, 10.04.2020. (Online) https:// rg.ru/2020/04/10/moscow-ukaz42-reg-dok.html (dostup 10.10.2020) [Указ мэра Москвы от 10 апреля 2020 года № 42-УМ «О внесении изменений в указ Мэра Москвы от 5 марта 2020 г. № 12-УМ». Российская газета, 10.04.2020. (Online) https://rg.ru/2020/04/10/moscowukaz42-reg-dok.html (доступ 10.10.2020)].

Ukaz mèra Moskvy ot 11 aprelâ 2020 goda № 43-UM «Ob utverždenii Porâdka oformleniâ i ispol'zovaniâ cifrovyh propuskov dlâperedviženiâ po territorii goroda Moskvy v perioddejstviâ režima povyšennoj gotovnosti v gorode Moskve». Российская газета, 11.04.2020. (Online) https://rg.ru/2020/04/11/moscow-ukaz43-reg-dok.html (dostup 10.10.2020) [Указ мэра Москвы от 11 апреля 2020 года № 43-УМ «Об утверждении Порядка оформления и использования цифровых пропусков для передвижения по территории города Москвы в период действия режима повышенной готовности в городе Москве». Российская газета, 11.04.2020. (Online) https://rg.ru/2020/04/11/moscow-ukaz43-reg-dok. html (доступ 10.10.2020)].

Ukaz mèra Moskvy ot 18 aprelâ 2020 goda № 44-UM «O vnesenii izmeneniâ v ukaz Mèra Moskvy ot 5 marta 2020 goda № 12-UM». Rossijskaâ gazeta, 11.04.2020. (Online) https:// rg.ru/2020/04/21/moscow-ukaz44-reg-dok.html (dostup 10.10.2020) [Указ мэра Москвы от 18 апреля 2020 года № 44-УМ «О внесении изменений в указ Мэра Москвы от 5 марта 2020 г. № 12-УМ». Российская газета, 11.04.2020. (Online) https://rg.ru/2020/04/21/moscowukaz44-reg-dok.html (доступ 10.10.2020)].

Ukaz mèra Moskvy ot 21 aprelâ 2020 goda № 47-UM «O vnesenii izmeneniâ v ukaz Mèra Moskvy ot 5 marta 2020 goda № 12-UM i ot 11 aprelâ 2020 g. №43-UM». Rossijskaâ gazeta, 11.04.2020. (Online) https://rg.ru/2020/04/21/mosocw-ukaz47-reg-dok.html (dostup 10.10.2020) [Указ мэра Москвы от 21 апреля 2020 года № 47-УМ «О внесении изменений в указы Мэра Москвы от 5 марта 2020 г. № 12-УМ и от 11 апреля 2020 г. № 43-УМ». Российская газета, 11.04.2020. (Online) https://rg.ru/2020/04/21/mosocw-ukaz47-reg-dok.html (доступ 10.10.2020)].

Ukaz mèra Moskvy ot 21 maâ 2020 goda № 59-UM «O vnesenii izmeneniâ v ukaz Mèra Moskvy ot 5 marta 2020 goda № 12-UM» Российская газета, 21.05.2020. (Online) https:// rg.ru/2020/05/21/moscow-ukaz59-reg-dok.html (dostup 10.10.2020) [Указ мэра Москвы от 21 мая 2020 года № 59-УМ «О внесении изменений в указ Мэра Москвы от 5 марта 2020 г. № 12-УМ». Российская газета, 21.05.2020. (Online) https://rg.ru/2020/05/21/moscowukaz59-reg-dok.html (доступ 10.10.2020)].

Ukaz mèra Moskvy ot 27 maâ 2020 goda № 61-UM «O vnesenii izmeneniâ v ukaz Mèra Moskvy ot 5 marta 2020 goda № 12-UM» Российская газета, 21.05.2020. (Online) https:// rg.ru/2020/05/27/moscow-ukaz61-reg-dok.html (dostup 10.10.2020) [Указ мэра Москвы от 27 мая 2020 года № 61-УМ «О внесении изменений в указ Мэра Москвы от 5 марта 2020 г. № 12-УМ». Российская газета, 21.05.2020. (Online) https://rg.ru/2020/05/27/moscowukaz61-reg-dok.html (доступ 10.10.2020)]. 
Ukaz mèra Moskvy ot 8 iûnâ 2020 goda № 68-UM «Ob ètapah snâtiâ ograničenij, ustanovlennyh v svâzi s vvedeniem režima povyšennoj gotovnosti». Российская газета, 21.05.2020. (Online) https://rg.ru/2020/06/08/moscow-ukaz68-reg-dok.html (dostup 10.10.2020) [Указ мэра Москвы от 8 июня 2020 года № 68-УМ «Об этапах снятия ограничений, установленных в связи с введением режима повышенной готовности». Российская газета, 21.05.2020. (Online) https://rg.ru/2020/06/08/moscow-ukaz68-reg-dok.html (доступ 10.10.2020)].

Ukaz mèra Moskvy ot 22 iûnâ 2020 goda № 74-UM «O vnesenii izmeneniâ v ukaz Mèra Moskvy ot 5 marta 2020 goda i ot 8 iûnâ 2020 g. № 68-UM». Российская газета, 21.05.2020. (Online) https://rg.ru/2020/06/22/moscow-ukaz74-reg-dok.html (dostup 10.10.2020) [Указ мэра Москвы от 22 июня 2020 года № 74-УМ «О внесении изменений в указы Мэра Москвы от 5 марта 2020 г. № 12-УМ и от 8 июня 2020 г. № 68-УМ». Российская газета, 21.05.2020. (Online) https://rg.ru/2020/06/22/moscow-ukaz74-reg-dok.html (доступ 10.10.2020)].

Competing interests: The author declares that she has no competing interests. 